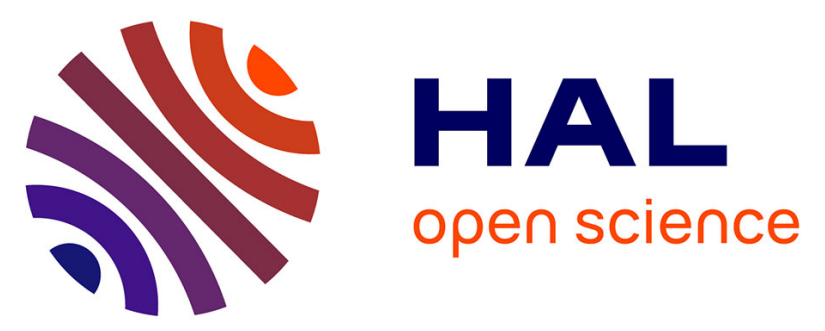

\title{
Convection Effects During Bulk Transparent Alloy Solidification in DECLIC-DSI and Phase-Field Simulations in Diffusive Conditions
}

\author{
F.L. Mota, Y. Song, J. Pereda, B. Billia, D. Tourret, J.-M. Debierre, R. \\ Trivedi, A. Karma, N. Bergeon
}

\section{To cite this version:}

F.L. Mota, Y. Song, J. Pereda, B. Billia, D. Tourret, et al.. Convection Effects During Bulk Transparent Alloy Solidification in DECLIC-DSI and Phase-Field Simulations in Diffusive Conditions. JOM Journal of the Minerals, Metals and Materials Society, 2017, 69 (8), pp.1280-1288. 10.1007/s11837017-2395-6 . hal-01637151

\section{HAL Id: hal-01637151 https://hal.science/hal-01637151}

Submitted on 24 May 2018

HAL is a multi-disciplinary open access archive for the deposit and dissemination of scientific research documents, whether they are published or not. The documents may come from teaching and research institutions in France or abroad, or from public or private research centers.
L'archive ouverte pluridisciplinaire HAL, est destinée au dépôt et à la diffusion de documents scientifiques de niveau recherche, publiés ou non, émanant des établissements d'enseignement et de recherche français ou étrangers, des laboratoires publics ou privés. 
Dear Author,

Here are the proofs of your article.

- You can submit your corrections online, via e-mail or by fax.

- For online submission please insert your corrections in the online correction form. Always indicate the line number to which the correction refers.

- You can also insert your corrections in the proof PDF and email the annotated PDF.

- For fax submission, please ensure that your corrections are clearly legible. Use a fine black pen and write the correction in the margin, not too close to the edge of the page.

- Remember to note the journal title, article number, and your name when sending your response via e-mail or fax.

- Check the metadata sheet to make sure that the header information, especially author names and the corresponding affiliations are correctly shown.

- Check the questions that may have arisen during copy editing and insert your answers/ corrections.

- Check that the text is complete and that all figures, tables and their legends are included. Also check the accuracy of special characters, equations, and electronic supplementary material if applicable. If necessary refer to the Edited manuscript.

- The publication of inaccurate data such as dosages and units can have serious consequences. Please take particular care that all such details are correct.

- Please do not make changes that involve only matters of style. We have generally introduced forms that follow the journal's style.

Substantial changes in content, e.g., new results, corrected values, title and authorship are not allowed without the approval of the responsible editor. In such a case, please contact the Editorial Office and return his/her consent together with the proof.

- If we do not receive your corrections within $\mathbf{4 8}$ hours, we will send you a reminder.

- Your article will be published Online First approximately one week after receipt of your corrected proofs. This is the official first publication citable with the DOI. Further changes are, therefore, not possible.

- The printed version will follow in a forthcoming issue.

\section{Please note}

After online publication, subscribers (personal/institutional) to this journal will have access to the complete article via the DOI using the URL: http://dx.doi.org/[DOI].

If you would like to know when your article has been published online, take advantage of our free alert service. For registration and further information go to: http://www.link.springer.com.

Due to the electronic nature of the procedure, the manuscript and the original figures will only be returned to you on special request. When you return your corrections, please inform us if you would like to have these documents returned. 


\section{Metadata of the article that will be visualized in OnlineFirst}

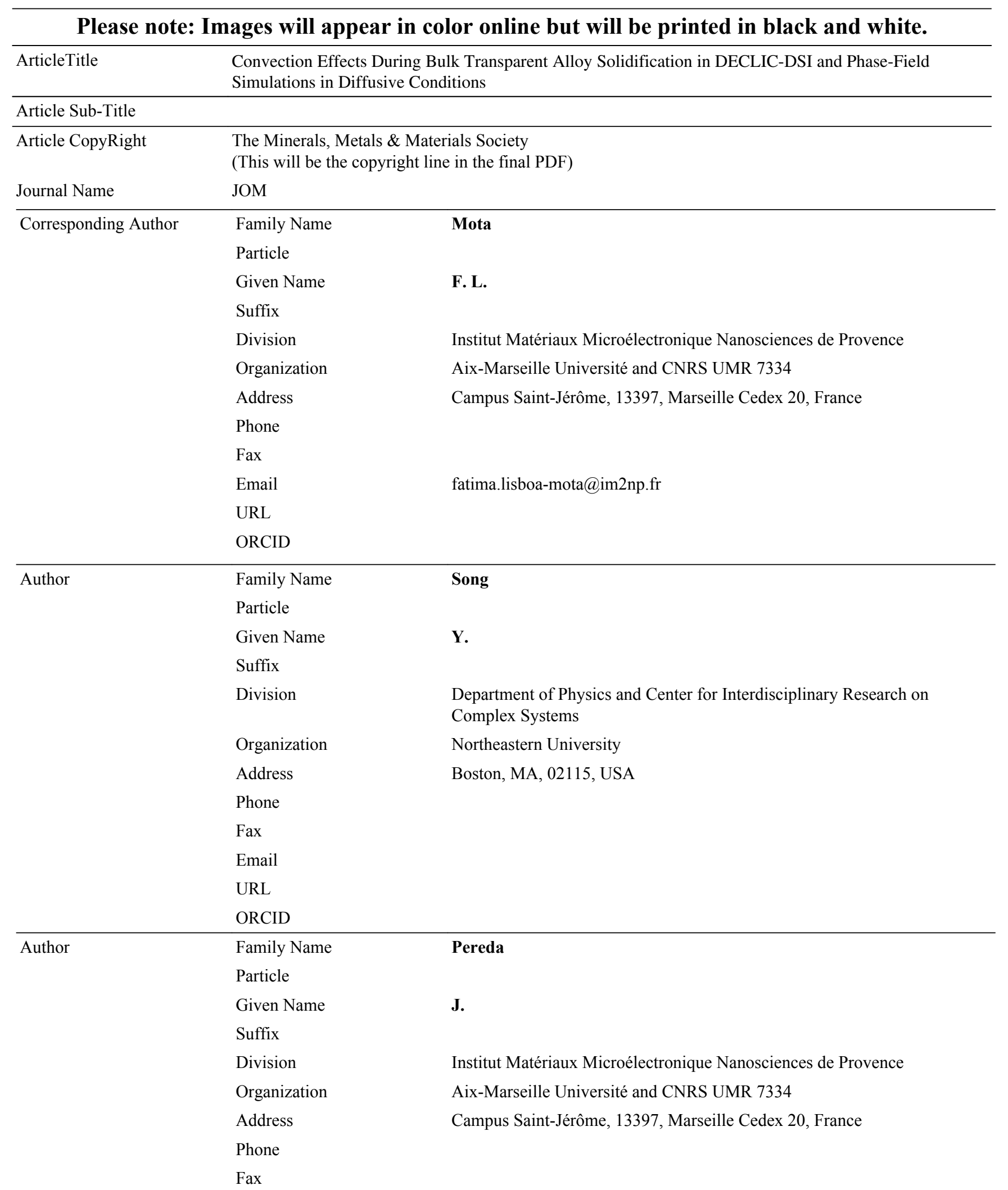


Email

URL

ORCID

\begin{tabular}{|c|c|c|}
\hline \multirow[t]{12}{*}{ Author } & Family Name & Billia \\
\hline & Particle & \\
\hline & Given Name & B. \\
\hline & Suffix & \\
\hline & Division & Institut Matériaux Microélectronique Nanosciences de Provence \\
\hline & Organization & Aix-Marseille Université and CNRS UMR 7334 \\
\hline & Address & Campus Saint-Jérôme, 13397, Marseille Cedex 20, France \\
\hline & Phone & \\
\hline & Fax & \\
\hline & Email & \\
\hline & URL & \\
\hline & ORCID & \\
\hline \multirow[t]{12}{*}{ Author } & Family Name & Tourret \\
\hline & Particle & \\
\hline & Given Name & D. \\
\hline & Suffix & \\
\hline & Division & \\
\hline & Organization & Los Alamos National Laboratory \\
\hline & Address & Los Alamos, NM, 87545, USA \\
\hline & Phone & \\
\hline & Fax & \\
\hline & Email & \\
\hline & URL & \\
\hline & ORCID & \\
\hline \multirow[t]{12}{*}{ Author } & Family Name & Debierre \\
\hline & Particle & \\
\hline & Given Name & J.-M. \\
\hline & Suffix & \\
\hline & Division & Institut Matériaux Microélectronique Nanosciences de Provence \\
\hline & Organization & Aix-Marseille Université and CNRS UMR 7334 \\
\hline & Address & Campus Saint-Jérôme, 13397, Marseille Cedex 20, France \\
\hline & Phone & \\
\hline & Fax & \\
\hline & Email & \\
\hline & URL & \\
\hline & ORCID & \\
\hline \multirow[t]{6}{*}{ Author } & Family Name & Trivedi \\
\hline & Particle & \\
\hline & Given Name & R. \\
\hline & Suffix & \\
\hline & Division & Department of Materials Science and Engineering \\
\hline & Organization & Iowa State University \\
\hline
\end{tabular}


Address

Ames, IA, 50010, USA

Phone

Fax

Email

URL

ORCID

\begin{tabular}{|c|c|c|}
\hline \multirow[t]{12}{*}{ Author } & Family Name & Karma \\
\hline & Particle & \\
\hline & Given Name & A. \\
\hline & Suffix & \\
\hline & Division & $\begin{array}{l}\text { Department of Physics and Center for Interdisciplinary Research on } \\
\text { Complex Systems }\end{array}$ \\
\hline & Organization & Northeastern University \\
\hline & Address & Boston, MA, 02115, USA \\
\hline & Phone & \\
\hline & Fax & \\
\hline & Email & \\
\hline & URL & \\
\hline & ORCID & \\
\hline \multirow[t]{13}{*}{ Author } & Family Name & Bergeon \\
\hline & Particle & \\
\hline & Given Name & N. \\
\hline & Suffix & \\
\hline & Division & Institut Matériaux Microélectronique Nanosciences de Provence \\
\hline & Organization & Aix-Marseille Université and CNRS UMR 7334 \\
\hline & Address & Campus Saint-Jérôme, 13397, Marseille Cedex 20, France \\
\hline & Phone & \\
\hline & Fax & \\
\hline & Email & \\
\hline & URL & \\
\hline & ORCID & \\
\hline & Received & 5 April 2017 \\
\hline \multirow[t]{2}{*}{ Schedule } & Revised & \\
\hline & Accepted & 12 May 2017 \\
\hline Abstract & \multicolumn{2}{|c|}{$\begin{array}{l}\text { To study the dynamical formation and evolution of cellular and dendritic arrays under diffusive growth } \\
\text { conditions, three-dimensional (3D) directional solidification experiments were conducted in microgravity } \\
\text { on a model transparent alloy onboard the International Space Station using the Directional Solidification } \\
\text { Insert in the Device for the study of Critical Liquids and Crystallization. Selected experiments were } \\
\text { repeated on Earth under gravity-driven fluid flow to evidence convection effects. Radial and axial } \\
\text { macrosegregation resulting from convection are observed in both ground experiments, and primary } \\
\text { spacings measured in ground and microgravity experiments are noticeably different. The microgravity } \\
\text { experiments provide unique benchmark data for numerical simulations of spatially extended pattern } \\
\text { formation under diffusive growth conditions. The results of 3D phase-field simulations highlight the } \\
\text { importance of accurately modeling thermal conditions that strongly influence the front recoil of the } \\
\text { interface and the selection of the primary spacing. The modeling predictions are in good quantitative } \\
\text { agreements with the microgravity experiments. }\end{array}$} \\
\hline Footnot & & \\
\hline
\end{tabular}


3 Convection Effects During Bulk Transparent Alloy Solidification Conditions

\section{INTRODUCTION}

Solidification microstructures play/an important role in the mechanical and physical properties of materials such as metallic alloys. The correlation between solidification microstructure and processing conditions can be examined by directional solidification experiments in which all parameters can be independently controlled. ${ }^{1,2}$ Most theoretical models have been developed considering diffusive heat and mass transport. These models have been validated by comparison with well-controlled experiments, most of which have been performed in thin samples to limit the extent of convection through confinement. In bulk samples, natural convection in the melt disturbs the homogeneity of processing conditions and, hence, microstructure formation. ${ }^{3-7}$ Solidification experiments under low-gravity conditions provide an exceptional tool to investigate interfacial pattern formation and solidification microstructure development in spatially extended samples with negligible convection and under wellcontrolled growth conditions. Those experiments provide unique benchmark data to validate the predictions of theoretical and computational models in a purely diffusive growth regime.

The present study comprises experiments performed in the Directional Solidification Insert (DSI) dedicated to in situ and real-time characterization of the dynamical selection of the solid-liquid interface morphology in bulk samples of transparent materials. It was developed by the French Space Agency (CNES) in the framework of the DECLIC project (Device for the study of Critical Liquids and Crystallization). The DECLIC facility was installed onboard the International Space Station (ISS) as part of a joint NASA/CNES research program. A series of microgravity experiments was performed

\begin{tabular}{|l|lll|}
\hline Journal : 11837_JOM & Dispatch : 24-5-2017 & Pages : 9 \\
& & $\square$ LE & $\square$ TYPESET \\
\hline
\end{tabular}


69 from April 2010 to April 2011, which were followed 70 and controlled remotely in near real-time condi71 tions. The favorable conditions provided by micro72 gravity allowed us to observe for the first time the 73 dynamics of extended oscillating cellular patterns 74 that were further investigated by three-dimensional 75 (3D) phase-field simulations. ${ }^{8-10}$ Significant differ76 ences between the behavior of extended oscillating 77 patterns and confined patterns in thin samples ${ }^{19}$ 78 were evidenced, stressing the importance of pattern 79 dimensionality. The DSI was then brought back on 80 ground and experiments were performed with sim81 ilar control parameters as in microgravity.

The aim of this article is to analyze directional solidification experiments realized under microgravity and under Earth's gravity with similar control parameters to address the effect of natural convection on interface patterns. The article is organized as follows. We first briefly describe the experimental apparatus and procedure as well as the characteristics of convection on Earth during upward solidification experiments and summarize the phase-field simulation methodology. We then present the results for the interface recoil (i.e., the time evolution of the axial interface position) and the axial macrosegregation. The results demonstrate that including the effects of thermal diffusion and latent heat rejection at the interface in phasefield simulations, so as to model accurately the spatiotemporal evolution of the thermal field in the experimental bulk samples, is necessary in predicting the front recoil. The comparison of Earth and microgravity front recoils further reveals the existence of a typical convecto-diffusive macrosegregation profile on Earth and, more surprisingly, even for microgravity experiments at a small growth rate. Next, we present the results pertaining to pattern formation. We first characterize the wellknown shift of the planar-to-cellular velocity threshold resulting from convection. ${ }^{12-14}$ We then show the existence of radial macrosegregation by analyzing the primary spacing distribution, and we characterize fluid flow effects on stationary primary spacings. In contrast to previous observations in metallic systems, ${ }^{15,16}$ we find here that suppression of convection in microgravity leads to smaller spacings than in ground-based experiments. Finally, we compare spacings observed in microgravity and predicted in phase-field simulations. We find that accurate modeling of the thermal field also improves the quantitative agreement between measured and predicted spacings.

\section{2}

phase changes. The cylindrical crucible has an inner diameter of $10 \mathrm{~mm}$ and a length that enables about $10 \mathrm{~cm}$ of solidification, allowing the study of the whole development of extended patterns from their initial stages up to the steady growth regime.

Figure 1 shows a representation of the optical apparatus, where the experimental cartridge is reduced to a cylinder with the liquid on top and solid at the bottom. In situ continuous observation led to a large number of images, and bespoke systematic image analysis procedures were developed. The main observation mode (axial) takes advantage of the complete transparency of the experimental cartridge: The light coming from LEDs passes through the cartridge from the bottom to the top, crossing the interface whose image is formed on a charge-coupled device (CCD) camera. Examples of cellular and dendritic patterns are given in Fig. 1. The top-view images of the interface are used to study array dynamics and characteristics, such as the primary spacing, i.e., the center-tocenter distance between two first-neighbor cells. On the same axis, a Mach-Zehnder interferometer with a $\mathrm{He}-\mathrm{Ne}$ laser produces interferometric images (examples in Fig. 2) used for three-dimensional reconstruction of microstructures. ${ }^{18}$ Additionally, the transverse observation mode provides side-view interface images (examples in Fig. 3), which allow a real-time characterization of interface motion and macroscopic shape.

The studied organic transparent compound was a succinonitrile (SCN)-0.24 wt.\% camphor alloy prepared with SCN purified by NASA by successive distillation and zone melting. Every step of sample preparation was carefully realized under vacuum to avoid humidity contamination. Solidification was performed by pulling the experimental cartridge from the hot zone toward the cold zone at a constant rate $V$ in a range between 0.1 and $30 \mu \mathrm{m} / \mathrm{s}$. A thermal gradient $G$ ranging from $10 \mathrm{~K} / \mathrm{cm}$ to $30 \mathrm{~K} /$ $\mathrm{cm}$ was imposed by regulated hot and cold zones, which were located above and below the adiabatic area where the interface was positioned. Further details about the experimental procedure can be found in previous articles. ${ }^{19,20}$

Phase-field ( $\mathrm{PF}$ ) modeling is a powerful computational approach to solving a challenging free-boundary problem and to simulating the dynamics of complex interfaces. ${ }^{21-24}$ The quantitative PF model used here has been developed over the past decades to explore quantitatively a variety of microstructure dynamics during alloy solidification. This model exploits a thin-interface asymptotic analysis ${ }^{25,26}$ and an anti-trapping current ${ }^{27,28}$ to model accurately the solid-liquid interface dynamics with a computationally tractable diffuse interface width much larger than the width of the actual physical interface. ${ }^{25,26}$ Using the latest three-dimensional implementation of this model parallelized on graphics processing units, $8,10,12$ we considered three different descriptions of the thermal field to assess its

\begin{tabular}{|l|lll|}
\hline & Journal : 11837_JOM & Dispatch : 24-5-2017 & Pages : 9 \\
& & $\square$ LE & $\square$ TYPESET \\
\hline Article No.: 2395 & $\square$ CP & $\square$ DISK \\
\hline
\end{tabular}


Convection Effects During Bulk Transparent Alloy Solidification in DECLIC-DSI and PhaseField Simulations in Diffusive Conditions

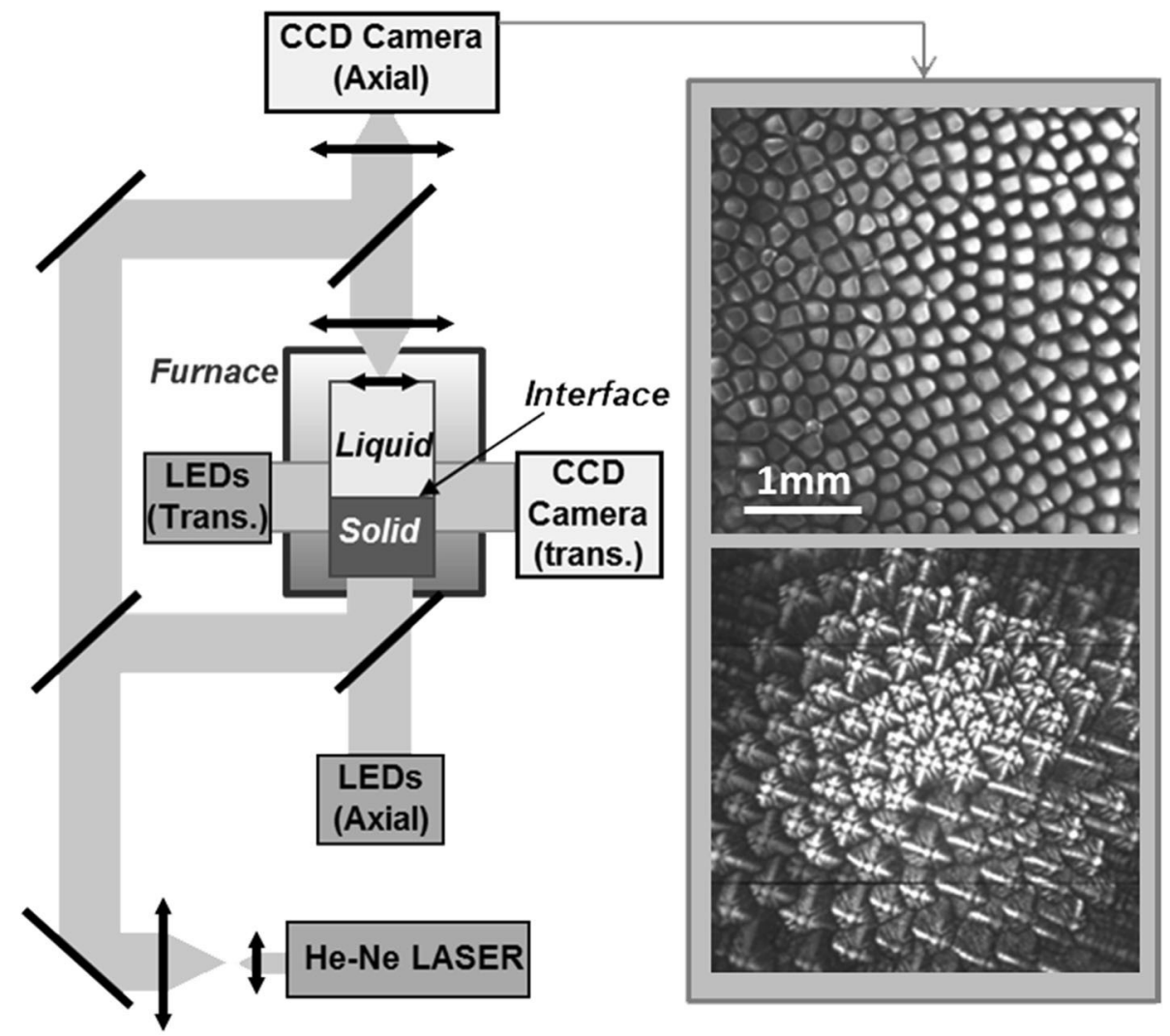

Fig. 1. Representation of the optical apparatus of the DECLIC-DSI (left). Examples of cellular and dendritic patterns obtained under microgravity (right).

189 influence on interface recoil and microstructure 190 formation. First, the widely used frozen tempera191 ture approximation (FTA) assumes a constant tem192 perature gradient translating uniformly at the 193 sample pulling velocity. Second, the thermal drift 194 approximation (TDA) models phenomenologically the drift of isotherms evidenced experimentally with fit parameters extracted from experimental measurements. ${ }^{20}$ Third, a time-dependent thermal field calculation (TFC) that is completely free of fit parameters couples the evolution equations of the phase field and solute field to a full time-dependent

\begin{tabular}{|l|lll|}
\hline & Journal : 11837_JOM & Dispatch : 24-5-2017 & Pages : $\mathbf{9}$ \\
& & $\square$ LE & $\square$ TYPESET \\
& Article No.: 2395 & $\square$ CP & $\varangle$ DISK \\
\hline
\end{tabular}




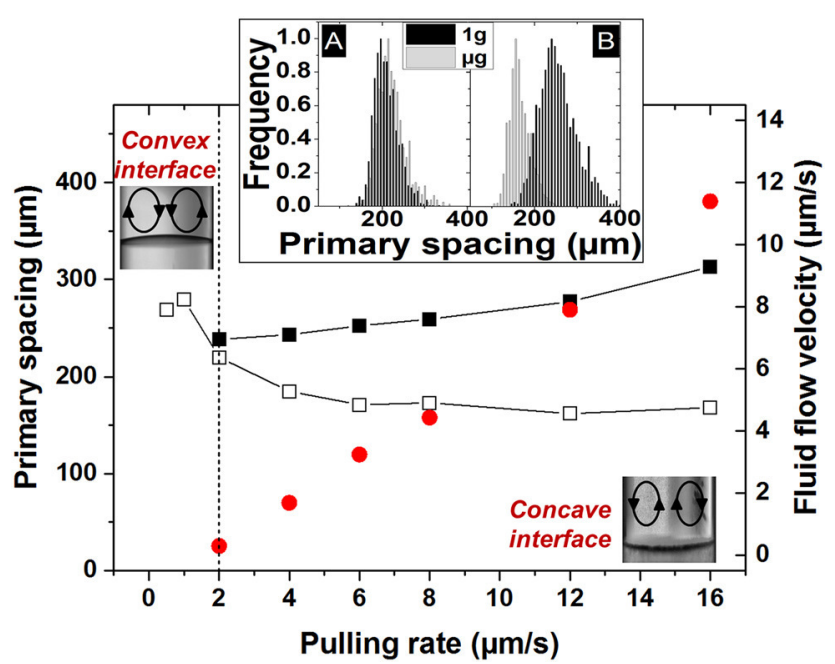

Fig. 3. Primary spacing as a function of pulling rate under microgravity $(T)$ and on Earth ( $\mathbf{\square})$. Right $Y$ axis: evolution of upward fluid flow velocity $(\mathbf{O})$. Insets: primary spacing histograms for $\mathrm{V}=2(\mathrm{~A})$ and $12 \mu \mathrm{m} / \mathrm{s}$ (B); examples of macroscopic interface shape with corresponding convection loops $(\mathrm{G}=19 \mathrm{~K} / \mathrm{cm})$.

201

202

203

204

205

206

207

208

209

210

211

212

213

214

215

216

217

218

219

220

221

222

223 calculation of axial (1D) thermal diffusion in the adiabatic zone. This calculation assumes that the temperature field is radially uniform and includes latent heat release at the interface. PF simulations use similar parameters as in our recent studies, 9,10 and details of the thermal field calculation will be presented elsewhere.

\section{RESULTS}

The microstructure formation was studied starting from the interface at rest until its stationary state, for a thermal gradient of $19 \mathrm{~K} / \mathrm{cm}$ and pulling rates ranging from $0.5 \mu \mathrm{m} / \mathrm{s}$ to $16 \mu \mathrm{m} / \mathrm{s}$. The first stages of solidification have fast dynamics with the transient development of microstructure, followed by a stationary state growth characterized by a stable spacing even if the patterns keep evolving in terms of topological order. Description of microstructures, primary spacing evolution, and mechanisms of adjustment can be found elsewhere. $^{29}$ Different effects of convection, found by comparative experiments on ground (upward growth, V//-g) and under microgravity, are analyzed in the next subsections.

\section{The Origin of Curvature and Resulting Macroscopic Effects}

At rest, the planar solid-liquid interface is located close to the liquidus temperature of the alloy. Its macroscopic interface shape is determined by the isotherm shape, usually curved in $3 \mathrm{D}$. The interface is convex (inset in the top-left of Fig. 3) for both thermal gradients, meaning that the crucible receives heat from the outside. Consequently, the liquid at the border of the crucible is hotter than in the center.
Once a pulling rate is applied, the interface moves closer to the cold zone and isotherms become concave. Moreover, as a result of the low thermal conductivity of the alloy compared with the quartz crucible, evacuation of latent heat generated during growth mainly occurs through the crucible, thus, inducing a thermal radial gradient from the border (colder) to the center (hotter) of the crucible. The interface then progressively becomes more concave (inset in the bottom-right of Fig. 3) as velocity increases. Lastly, isotherms are shifted downward by heat transport in the cartridge, also leading to an increase of concavity. Both effects are approximately proportional to the pulling rate as detailed in a previous study. ${ }^{20}$

On the ground, the radial thermal gradient induces thermal convection. ${ }^{30}$ For convex interfaces, the hotter liquid with lower density at the border is driven upward by buoyancy, so that a toric convection loop, ascending at the border and descending in the center, is formed. For concave interfaces, the liquid in the center is hotter, so that fluid flow rises in the center of the crucible. The fluid flow direction is schematically represented in the top-left and bottom-right insets of Fig. 3, respectively, for convex and concave interfaces.

Interface Motion and Axial Macrosegregation

When pulling of the sample at a constant velocity $V$ is initiated, the interface recoils within the temperature frame, and the solute concentration builds up on the liquid side of the interface. This interface motion from rest to its steady-state position is referred to as the front recoil. The planar front undergoes the Mullins-Sekerka instability ${ }^{31,32}$ when the solute concentration gradient in front of the interface $G_{\mathrm{c}}$ exceeds the critical value $\mathrm{G} / m_{\mathrm{L}}$, with $m_{\mathrm{L}}$ the alloy liquidus slope. This initial interface dynamics before the destabilization of the planar front can usually be well predicted by the Warren-Langer model. ${ }^{33}$

Figure 4a gives an example of the experimental interface recoil for $V=4 \mu \mathrm{m} / \mathrm{s}$ ( $\mu \mathrm{g}$ experiment) obtained from transverse observation, focused on the initial solidification stage. The three different thermal descriptions, namely, FTA, TDA, and TFC are compared with the experimental measurements. The FTA calculation, representative of the classic Warren-Langer model, ${ }^{33}$ underestimates both the recoil rate and its final extent compared with present experiments. Other phase-field simulations using the TDA or the TFC provide a much better agreement with experiments. Not only is the time evolution of the interface position better estimated, but the time for the occurrence of the morphological instability $(L \sim 1.88 \mathrm{~mm}$ for the TDA and $1.76 \mathrm{~mm}$ for the TFC) is also in much better quantitative agreement with experimental observations (1.55 mm $<L<1.96 \mathrm{~mm})$. Steady-state cell/dendrite tip positions after morphological instability

\begin{tabular}{|l|lll|}
\hline & Journal : 11837_JOM & Dispatch : 24-5-2017 & Pages : 9 \\
& & $\square$ LE & $\square$ TYPESET \\
\hline Article No.: 2395 & $\square$ CP & $\square$ DISK \\
\hline
\end{tabular}


Convection Effects During Bulk Transparent Alloy Solidification in DECLIC-DSI and PhaseField Simulations in Diffusive Conditions
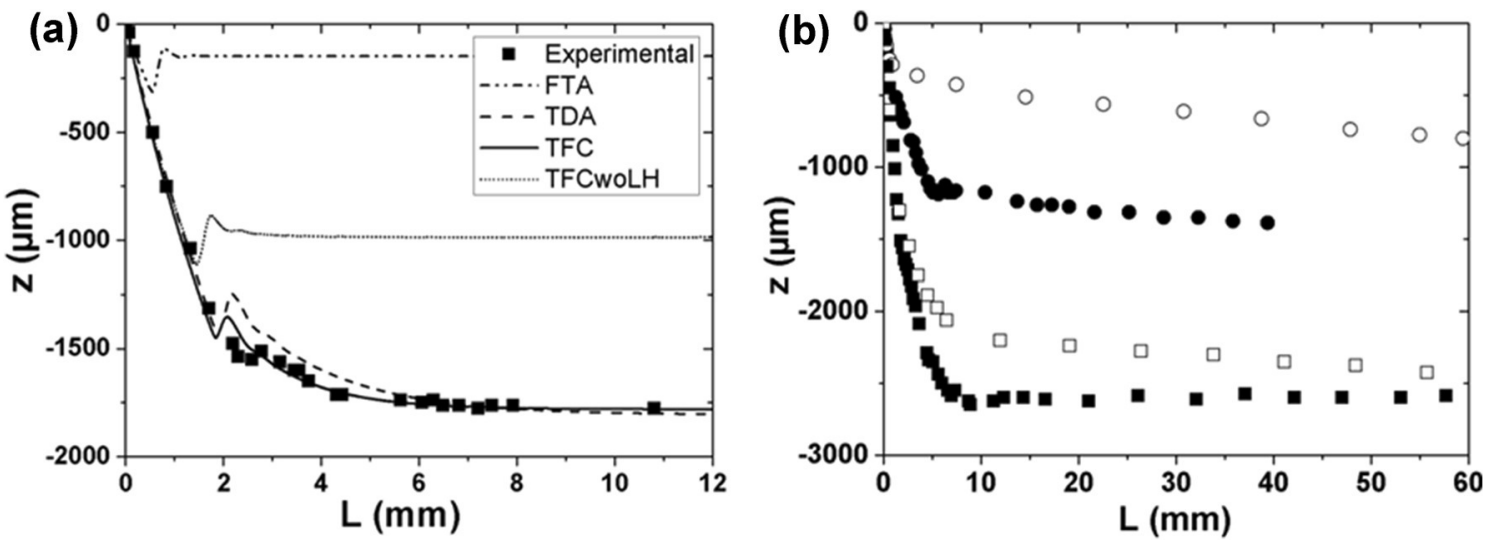

Fig. 4. Interface position $(z)$ as a function of solidified length $(L=V t)$. (a) The experimental interface dynamics at $V=4 \mu \mathrm{m} / \mathrm{s}$ is compared with PF simulations with different thermal conditions. (b) Comparison between results obtained under microgravity (full symbols) and on the ground (empty symbols) for $V=8$ (squares) and $0.5 \mu \mathrm{m} / \mathrm{s}$ (circles) $(\mathrm{G}=19 \mathrm{~K} / \mathrm{cm})$.

are also well predicted. Note that the coupled TFC provides a better estimation than the phenomenological TDA, while involving no adjustable fit parameter. Furthermore, the TFC simulation neglecting latent heat rejection contribution (TFCwoLH in Fig. 4a) underestimates the steady-state interface position, thereby clearly demonstrating the critical influence of latent heat rejection on the recoil of the interface.

Since the interface grows in local thermodynamic equilibrium, solute interfacial composition variations in the liquid induce similar variations of composition in the solid. The solute build-up during planar front recoil, and the subsequent transient development of patterns of cells or dendrites before a steady-state growth regime is reached, is a first cause of axial macrosegregation. If the interface temperature keeps evolving, meaning that steady state is not reached, an additional source of axial macrosegregation, such as convection, must be considered.

In Fig. 4b, the fast motion characterizing the initial transient is similar on the ground and in microgravity, but the interface decelerates earlier on the ground. Depending on processing conditions, it may then stabilize at a steady-state position or keep drifting slowly with time. Stabilization (i.e., $\mu \mathrm{g}-V=8 \mu \mathrm{m} / \mathrm{s}$ in Fig. $4 \mathrm{~b}$ ) corresponds to a plateau of concentration reached after the initial transient: It is typical of a purely diffusive mode, and most microgravity results follow this tendency. The absence of stabilization corresponds to a characteristic "S-shape" macrosegregation profile, typical of a convecto-diffusive growth mode. ${ }^{34}$ This evolution is observed for ground experiments (i.e., $1 \mathrm{~g}-V=0.5$ and $8 \mu \mathrm{m} / \mathrm{s}$ in Fig. 4b) but also surprisingly for microgravity experiments performed at the lowest pulling rate (i.e., $\mu \mathrm{g}-V=0.5 \mu \mathrm{m} / \mathrm{s}$ in Fig. $4 \mathrm{~b}$ ). For these conditions, an order of magnitude analysis of fluid flow ${ }^{35,36}$ revealed that diffusive conditions would be obtained if the gravity in ISS was actually $10^{-6} \mathrm{~g}$ (Fig. 13 of Mota et al. ${ }^{20}$ ), but as it is much closer to $10^{-3} \mathrm{~g}$ or $10^{-4} \mathrm{~g}$, experiments performed at low velocities still appear to be affected by residual convection.

\section{Pattern Development and Spacing Selection}

For the lowest studied pulling rate, i.e., $0.5 \mu \mathrm{m} / \mathrm{s}$, significant differences were found between ISS and ground experiments. Cells are fully developed under microgravity, whereas on the ground, the interface is still smooth, indicating that the critical velocity from planar to cellular interface is shifted toward higher velocity on the ground. This shift of planar stability at higher velocities (for $k<1$ ) resulting from liquid convection was already evidenced theoretically $^{12,37}$ and experimentally. ${ }^{12-14}$

A classic approach to assessing the effect of liquid convection consists of considering a diffusive boundary layer in the liquid close to the solid-liquid interface, as initially introduced by Burton et al. ${ }^{38}$. Fluid flow reduces the thickness $\delta$ of the boundary layer where transport is diffusive in front of the interface; the concentration ahead of this boundary layer is considered homogeneous and well mixed at the nominal concentration. Solute conservation then implies the decrease of the liquid solute concentration at the interface compared with pure diffusive conditions. The solute concentration in the solid also decreases because it is proportional to the concentration in the liquid by the partition coefficient $k$. The driving force for the interface instability is thus reduced inducing a stabilization of the interface and an increase of the critical velocity (see, e.g., Clarke et al. ${ }^{12}$ and its supplementary material for a discussion and an analytical derivation of the constitutional supercooling criterion in the presence of a diffusive boundary layer).

The interface instability driving force on ground $m_{\mathrm{L}} \cdot G_{\mathrm{c}, \text { conv }}$ can be written as $k_{\mathrm{eff}} m_{\mathrm{L}} \cdot G_{\mathrm{c} \text {,diff }}$ where $G_{\mathrm{c}}$ is the concentration gradient at the interface and $k_{\text {eff }}$ is the effective partition coefficient defined as the ratio between the solute concentration in the solid at the

\begin{tabular}{|l|lll|}
\hline \multirow{2}{*}{ Journal : 11837_JOM } & Dispatch : 24-5-2017 & Pages : $\mathbf{9}$ \\
& & $\square$ LE & $\square$ TYPESET \\
\hline
\end{tabular}


interface and in the liquid far from the interface. $k_{\text {eff }}$ tends toward 1 in purely diffusive conditions and toward the partition coefficient $k$ in convectiondominated conditions. The effective segregation coefficient can then be estimated as the ratio between the critical velocities under microgravity and on the ground. An estimation of critical velocities is performed using the instantaneous interface velocity obtained following the interface position by side-view observation, combined to top-view observation to detect instability triggering. Onboard the ISS, the critical velocity is $0.48 \mu \mathrm{m} / \mathrm{s}$ and on the ground $0.95 \mu \mathrm{m} / \mathrm{s}$, which leads to a $k_{\text {eff }}$ of 0.51 . This is a sign of partial mixing of the bulk liquid by convection during solidification. As mentioned, the critical velocity measured onboard the ISS at $V=0.5 \mu \mathrm{m} / \mathrm{s}$ may be affected by residual convection: the value of $k_{\text {eff }}=0.51$ is then slightly overestimated as $k_{\text {eff }}$ should be calculated using a critical velocity determined in a purely diffusive growth regime.

The onset of morphological instability is shown on Fig. 2 by interferometry top-view observations. Under microgravity, destabilization occurs homogeneously over the whole interface; for upward growth on ground, instability starts near the border and progressively propagates toward the center. A similar effect of inhomogeneous triggering was previously observed for succinonitrile-acetone alloys but for a macroscopically concave interface. ${ }^{39}$ In this case, microstructures first developed in a small region near the center of the interface, and the inward radial transport of solute by fluid flow eventually led to a solute accumulation in the center where instability first developed. In the present study, from rest up to morphological instability, regardless of experimental conditions, the interface is macroscopically convex (i.e., with convection descending in the center). The radial concentration gradient induced by fluid flow is opposite compared with the case of a concave interface. Morphological instability thus triggers at the border and propagates toward the center.

Morphological instability eventually leads to the formation and growth of cells, which compete until they reach a stable spacing. The radial concentration gradient induced by fluid flow also affects the final microstructure. Under microgravity, patterns are more homogeneous than on the ground where a radial size gradient from large cells in the center to small cells at the crucible border is observed. ${ }^{14,30,39}$ The size distribution histograms presented in Fig. 3 highlight those differences. At $12 \mu \mathrm{m} / \mathrm{s}$, the concave interface is associated with a noticeable convection on the ground that increases the average primary spacing but also enlarges the distribution. Conversely, at $2 \mu \mathrm{m} / \mathrm{s}$, the interface is macroscopically flat and the radial thermal gradient almost vanishes, so that even on ground conditions, thermal convection is very weak: the resulting peak and the width of size histograms are thus similar on the ground and under microgravity.
Comparative analyses of microgravity and ground experiments pertaining to primary spacing dependence on the pulling rate, presented in Fig. 3, also reveal major differences. Similar primary spacing values are found for a macroscopically flat interface $(2 \mu \mathrm{m} / \mathrm{s})$ as convection is weak. For higher pulling rates, spacing under microgravity is lower than on the ground. Such results may seem surprising because the results of previous studies on metallic systems pointed out spacing in microgravity larger than on the ground with a convergence when the pulling rate increases. ${ }^{15,16}$ The difference may come from the different origin of convection. As previously explained, in the studied transparent system, the radial thermal gradient, and associated concavity, is induced by the low conductivity of the sample compared with the crucible: The radial thermal gradient associated with concavity then increases with latent heat release, so fluid flow and its effect increase with pulling rate. In metallic systems, thermal convection stems from the difference of conductivities between the solid $\left(K_{\mathrm{S}}\right)$ and the liquid $\left(K_{\mathrm{L}}\right)$, with $K_{\mathrm{S}}>K_{\mathrm{L}}$, which promotes interface convexity. The latent heat diffusion effects are negligible because it is fast in the sample; when the pulling rate becomes large enough, the effect of fluid flow is thus negligible ${ }^{40}$ and the primary spacing is no longer affected by fluid flow. The current opposite effect of fluid flow on primary spacing can be attributed to the flow direction, resulting from the concavity or convexity of the interface: In metallic systems, the liquid sinks in the center and rises on the border, whereas it is the opposite in the currently studied transparent system.

Lehmann et al. Ref. ${ }^{41}$ explain the variation of primary spacing with fluid flow by the modification of the concentration of the interdendritic liquid. On this basis, they propose a relationship between the component of fluid flow velocity $U$ I parallel to the pulling velocity (here taken negative for a downward component) and the primary spacing $\lambda$ and $\lambda_{0}$, respectively, with and without influence of convection:

$$
U_{\|}=V\left[1-\left(\frac{\lambda}{\lambda_{0}}\right)^{2}\right]
$$

For a convex interface, flow is descending in the center so $U \mid<0$ and $\lambda_{0}>\lambda$ as observed in experiments in metallic systems. ${ }^{15,40}$ Equation 1 is primarily designed for downward flows, but its use can be extended to upward flows as long as the fluid velocity remains lower than the pulling rate. Using Eq. 1, we calculated fluid flow velocities $U \mid$ as a function of $V$, as plotted in Fig. 3 (right $y$ axis). At $2 \mu \mathrm{m} / \mathrm{s}, U \mid$ is almost zero, corresponding to the experimental conditions on the ground closer to pure diffusive transport; $U$ I increases with pulling rate (increase of concavity) leading to a progressively larger spacing on the ground compared with

\begin{tabular}{|l|lll|}
\hline & Journal : 11837_JOM & Dispatch : 24-5-2017 & Pages : $\mathbf{9}$ \\
& & $\square$ LE & $\square$ TYPESET \\
& Article No.: 2395 & $\square$ CP & $\square$ DISK \\
\hline
\end{tabular}


Convection Effects During Bulk Transparent Alloy Solidification in DECLIC-DSI and Phase-

Field Simulations in Diffusive Conditions

494 that in microgravity. The fluid flow velocity can

504

505

506 then be taken into account in the mass transfer equation, enabling expression of the convecto-diffusive parameter $\Delta=\frac{\delta V}{D}$, where $D$ is the solute diffusion coefficient in the liquid, as a function of fluid flow velocity $U I^{40,42}$ In this approach, $\Delta=1$ for a purely diffusive regime and tends to zero for highly convective regimes. The characteristic equation for the solutal boundary layer is then ${ }^{40,42}$ :

$$
\frac{D}{\delta V}=1+\frac{U_{\|}}{V}
$$

and the effective partition coefficient $k_{\text {eff }}$ initially expressed as a function of $\Delta$ then becomes, for an upward component of fluid flow:

$$
k_{\text {eff }}=\frac{k}{1-\frac{1-k}{1+\frac{U_{\|}}{V}}} .
$$

The evolution of $k_{\text {eff }}$ with pulling rate based on Fig. 3 data is presented in Fig. 5. Using the fluid flow velocities from Fig. 3 (right $y$ axis), $k_{\text {eff }}=1$ corresponds to a component $U I=0$, obtained for a pulling velocity of $1.9 \mu \mathrm{m} / \mathrm{s}$, which yields similar average primary spacing on the ground and in microgravity. For higher pulling rates, $k_{\text {eff }}$ decreases rapidly with $V$ in the vicinity of $k_{\mathrm{eff}}=1$ (i.e., $V \approx 1.9 \mu \mathrm{m} / \mathrm{s}$ ) before a very slow decrease around $k_{\text {eff }} \cong 0.2$, which is still far from a complete mixing that would correspond to $k_{\text {eff }}=k=0.07$, as assessed experimentally. ${ }^{43}$ The $k_{\text {eff }}$ determined through the ratio of critical velocities is additionally represented in Fig. 5. It should be remembered that it corresponds to a range of pulling velocities where the interface is convex. The progressive increase of

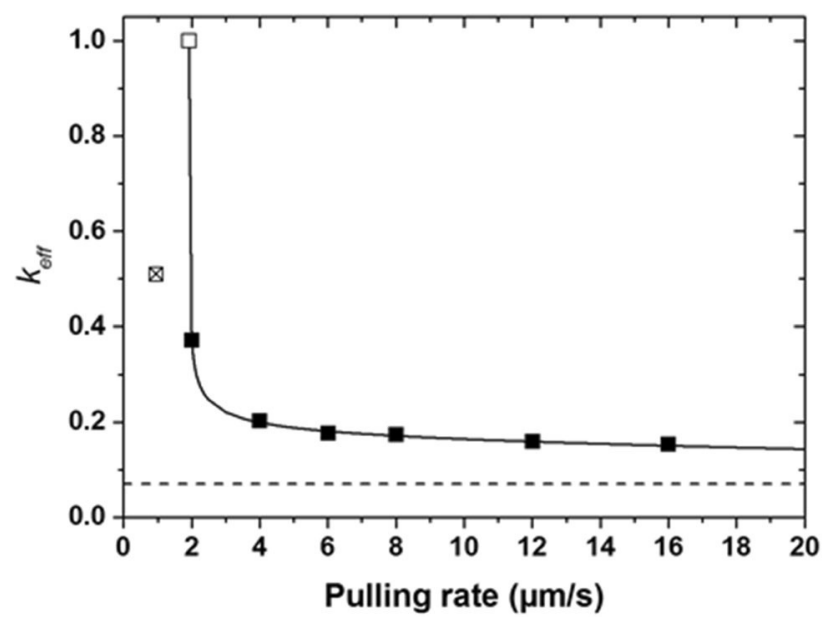

Fig. 5. Evolution of the effective partition coefficient $k_{\text {eff }}$ as a function of pulling rate: $x$, estimated from the ratio of critical velocity under microgravity and on the ground; $\mathbf{\square}$, estimated using experimental data on fluid flow velocity, where the solid line represents Eq. 3 for $V \geq 1.9 \mu \mathrm{m} / \mathrm{s}$, with the boundary condition $\mathrm{k}_{\text {eff }}=1$ for $\mathrm{V}=1.9 \mu \mathrm{m} / \mathrm{s}$ (T) when fluid flow is zero. The dashed line corresponds to $k=0.07$ assessed experimentally ${ }^{43}(\mathrm{G}=19 \mathrm{~K} / \mathrm{cm})$. latent heat release with pulling rate leads to the transition to the flat interface and eventually to a concave interface. This implies that for pulling rates lower than $1.9 \mu \mathrm{m} / \mathrm{s}, k_{\text {eff }}$ should increase to reach its maximum $\left(k_{\text {eff }}=1\right)$ at $V=1.9 \mu \mathrm{m} / \mathrm{s}$ before the decrease observed for higher pulling rates.

Primary spacing selection mechanisms have been extensively studied analytically and experimentally, mostly in thin sample geometries. ${ }^{44-48}$ In the specific case of the current DECLIC-DSI experiments, previous 3D PF simulations based on the FTA had so far fallen short of accurately predicting primary spacing. ${ }^{8-10}$ The region between the upper and lower bars in Fig. 6 shows the stable spacing ranges predicted by $\mathrm{PF}$ simulations using a similar procedure as in previous studies ${ }^{9,10,49}$ Stable spacing ranges are determined by the FTA as the steadystate thermal gradient is only weakly affected by the different thermal representations. All experimentally measured average spacings (squares) fall within the calculated stable spacing ranges. Although stability limits are similar for different thermal representations, the dynamically selected spacings within these limits in spatially extended simulations using the TFC (circles) are larger than with the FTA (diamonds). Hence, the more accurate TFC significantly improves the agreement between predicted and measured spacings. Nevertheless, experimental spacings remain slightly larger than in spatially extended PF simulations. This could be linked to additional uncertainties on exact alloy or processing parameters, as well as to a size effect in the PF simulations, for which only about seven cells in total were present in spatially extended TFC simulations for $V=2 \mu \mathrm{m} / \mathrm{s}$.

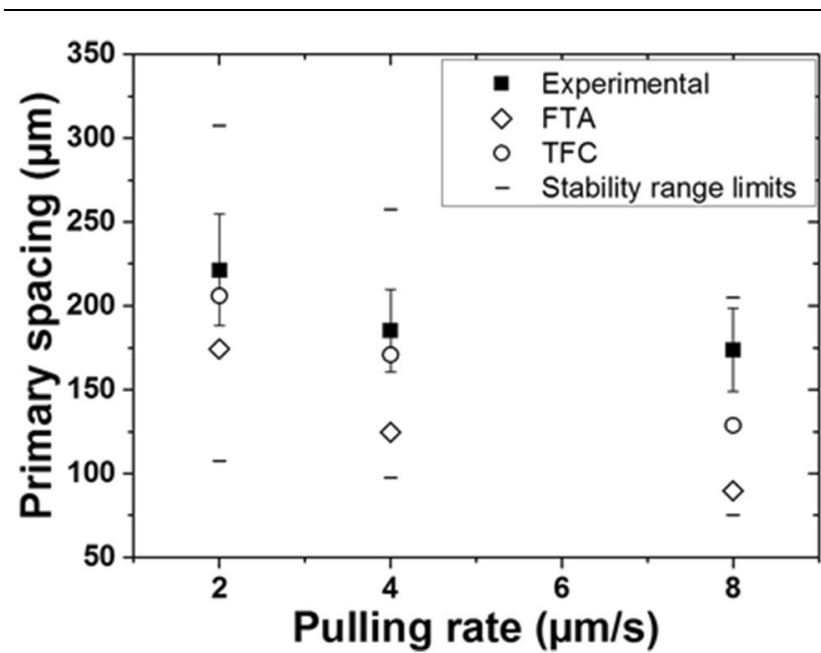

Fig. 6. Experimental average primary spacings with standard deviations (error bars) measured in microgravity experiments compared with selected average primary spacings obtained in PF simulations with a large system and different thermal conditions. Limits of calculated stable spacing ranges are plotted as short horizontal lines. All observed spacings in experiments and simulations fall inside the stable spacing ranges $(\mathrm{G}=19 \mathrm{~K} / \mathrm{cm})$.

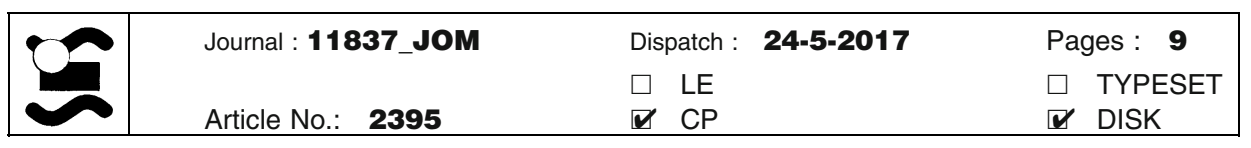




\section{CONCLUSION}

In this article, we presented results obtained with the Directional Solidification Insert of the DECLIC facility, dedicated to in situ and real-time observation of the solid-liquid interface during directional solidification of bulk transparent alloys. Solidification experiments were performed onboard the ISS to image the whole dynamics of microstructure formation and evolution under diffusive growth conditions. After the return of the DSI on the ground, comparative experiments were performed using the same control parameters to assess the influence of convection.

The comparison of microgravity and ground experiments highlighted the major effects of thermal convection at the macroscopic scale (both radial and axial macrosegregation) and at the microscopic scale (modification of the average primary spacing). In the bulk transparent system studied, the convection originates from a radial thermal gradient, which is highly sensitive to latent heat release. We demonstrated that the atypical effect of convection on primary spacing (continuous increase of spacing with pulling rate) compared with previous studies conducted in metallic systems ${ }^{15,35}$ stems from convection characteristics and, especially, from its sensitivity to latent heat release.

The reduced gravity environment of space provides unique conditions to obtain quantitative benchmark data with homogeneous patterns. By performing a quantitative comparison of those unique data and $3 \mathrm{D}$ phase-field simulations, we have demonstrated that accurate modeling of the thermal field within the adiabatic zone is essential to predicting quantitatively both the transient recoil of the planar interface and subsequent dynamical selection of the primary spacing. This is especially relevant to transparent organic compounds in bulk configuration.

\section{ACKNOWLEDGEMENTS}

The authors express their gratitude to CNES (Centre National d'Etudes Spatiales) and NASA (National Aeronautics and Space Administration) for the support received in the scientific projects MISOL3D (Microstructures de SOLidification 3D) and DSIP (Dynamical Selection of Interface Patterns). A.K. and R.T. were supported by NASA Grants NNX12AK54G and NNX16AB54G. D.T. gratefully acknowledges support of the U.S. Department of Energy through a Director's Postdoctoral Fellowship from the LANL/LDRD Program.

\section{REFERENCES}

1. B. Billia and R. Trivedi, Handbook of Crystal Growth, vol. 1 (Bristol: Elsevier, 1993), pp. 899-1074.

2. R. Trivedi, Y. Shen, and S. Liu, Advances in Materials and Materials Processing (New Delhi: Tata McGraw-Hill Publ. Ltd., 2001), pp. 42-49.

3. M.E. Glicksman, S.R. Coriell, and G.B. Mcfadden, Annu. Rev. Fluid Mech. 18, 307 (1986).
4. S.H. Davis, J. Fluid Mech. 212, 241 (1990).

5. G. Muller and A. Ostrogorsky, Handbook of Crystal Growth, vol. 2B (Amsterdam: Elsevier, 1994), p. 709.

6. M.D. Dupouy, D. Camel, and J.J. Favier, Acta Metall. 37, 1143 (1989).

7. H. Nguyen-Thi, G. Reinhart, and B. Billia, C. R. Mec. 345, 66 (2017)

8. N. Bergeon, D. Tourret, L. Chen, J.M. Debierre, R. Guerin, A. Ramirez, B. Billia, A. Karma, and R. Trivedi, Phys. Rev. Lett. 110, 6102 (2013).

9. J. Pereda, F.L. Mota, L. Chen, B. Billia, D. Tourret, Y. Song, J.M. Debierre, R. Guérin, A. Karma, R. Trivedi, and N. Bergeon, Phys. Rev. E 95, 2803 (2017).

10. D. Tourret, J.-M. Debierre, Y. Song, F.L. Mota, N. Bergeon, R. Guérin, R. Trivedi, B. Billia, and A. Karma, Phys. Rev. E 92, 2401 (2015).

11. M. Georgelin and A. Pocheau, Phys. Rev. Lett. 79, 2698 (1997).

12. A.J. Clarke, D. Tourret, Y. Song, S.D. Imhoff, P.J. Gibbs, J.W. Gibbs, K. Fezzaa, and A. Karma, Acta Mater. 129, 203 (2017).

13. G. Grange, J. Gastaldi, C. Jourdan, and B. Billia, J. Cryst. Growth 151, 192 (1995).

14. R. Trivedi, S. Liu, P. Mazumder, and E. Simsek, Sci. Technol. Adv. Mater. 2, 309 (2001).

15. B. Drevet, H. Nguyen-Thi, D. Camel, B. Billia, and M.D. Dupouy, J. Cryst. Growth 218, 419 (2000).

16. H. Nguyen-Thi, Y. Dabo, B. Drevet, M.D. Dupouy, D. Camel, B. Billia, J.D. Hunt, and A. Chilton, J. Cryst. Growth 281, 654 (2005).

17. G. Pont, S. Barde, B. Zappoli, F. Duclos, Y. Garrabos, C. Lecoutre, D. Beysens, B. Billia, N. Bergeon, N. Mangelinck, R. Marcout, and D. Blonde, 60th International Astronautical Congress (Daejeon: IAF, 2009).

18. N. Bergeon, C. Weiss, N. Mangelinck-Noel, and B. Billia Trans. Ind. Inst. Met. 62, 455 (2009).

19. N. Bergeon, A. Ramirez, L. Chen, B. Billia, J.H. Gu, and R. Trivedi, J. Mater. Sci. 46, 6191 (2011).

20. F.L. Mota, N. Bergeon, D. Tourret, A. Karma, R. Trivedi, and B. Billia, Acta Mater. 85, 362 (2015).

21. L.Q. Chen, Annu. Rev. Mater. Res. 32, 113 (2002).

22. W.J. Boettinger, J.A. Warren, C. Beckermann, and A. Karma, Annu. Rev. Mater. Res. 32, 163 (2002).

23. J.J. Hoyt, M. Asta, and A. Karma, Mater. Sci. Eng. $R$ 41, 121 (2003).

24. I. Steinbach, JOM 65, 1096 (2013).

25. A. Karma and W.J. Rappel, Phys. Rev. E 53, 3017 (1996).

26. A. Karma and W.J. Rappel, Phys. Rev. E 57, 4323 (1998).

27. A. Karma, Phys. Rev. Lett. 87, 5701 (2001).

28. B. Echebarria, R. Folch, A. Karma, and M. Plapp, Phys. Rev. E 70, 1604 (2004).

29. N. Bergeon, F.L. Mota, L. Chen, D. Tourret, J.M. Debierre, R. Guerin, A. Karma, B. Billia, and R. Trivedi, IOP Conf. Ser. Mater. Sci. Eng. 84, 012077 (2015).

30. C. Weiss, N. Bergeon, N. Mangelinck-Noel, and B. Billia, Mater. Sci. Eng. A 413, 296 (2005).

31. W.A. Tiller, K.A. Jackson, J.W. Rutter, and B. Chalmers, Acta Metall. 1, 428 (1953).

32. W. Mullins and R. Sekerka, J. Appl. Phys. 35, 444 (1964).

33. J.A. Warren and J.S. Langer, Phys. Rev. E 47, 2702 (1993).

34. J.J. Favier, Acta Metall. 29, 205 (1981).

35. D. Camel and J.J. Favier, J. Cryst. Growth 67, 42 (1984).

36. D. Camel and J.J. Favier, J. Cryst. Growth 67, 57 (1984).

37. S.R. Coriell, D.T.J. Hurle, and R.F. Sekerka, J. Cryst. Growth 32, 1 (1976).

38. J.A. Burton, R.C. Prim, and W.P. Slichter, J. Chem. Phys. 21, 1987 (1953).

39. H. Jamgotchian, N. Bergeon, D. Benielli, P. Voge, B. Billia, and R. Guerin, Phys. Rev. Lett. 87, 6105 (2001).

40. J.P. Garandet, J.J. Favier, and D. Camel, Handbook of Crystal Growth, vol. 2 (Bristol: Elsevier, 1994), pp. 659707.

41. P. Lehmann, R. Moreau, D. Camel, and R. Bolcato, J. Cryst. Growth 183, 690 (1998).

\begin{tabular}{|l|lll|}
\hline & Journal : 11837_JOM & Dispatch : 24-5-2017 & Pages : 9 \\
& & $\square$ LE & $\square$ TYPESET \\
\hline
\end{tabular}


Convection Effects During Bulk Transparent Alloy Solidification in DECLIC-DSI and PhaseField Simulations in Diffusive Conditions

42. S. Kaddeche, J.P. Garandet, C. Barat, H. BenHadid, and D Henry, J. Cryst. Growth 158, 144 (1996).

43. F.L. Mota, L.M. Fabietti, N. Bergeon, L.L. Strutzenberg, A Karma, B. Billia, and R. Trivedi, J. Cryst. Growth 447, 31 (2016).

44. R.N. Grugel and Y. Zhou, Metall. Trans. A 20, 969 (1989).

45. K. Somboonsuk, J.T. Mason, and R. Trivedi, Metall. Trans. A 15, 967 (1984).
46. R. Trivedi and K. Somboonsuk, Mater. Sci. Eng. 65, 65 (1984).

47. K. Somboonsuk and R. Trivedi, Acta Metall. 33, 1051 (1985).

48. R. Trivedi and K. Somboonsuk, Acta Metall. 33, 1061 (1985).

705

706

49. B. Echebarria, A. Karma, and S. Gurevich, Phys. Rev. E 81, 707 1608 (2010). 
Journal : 11837

Article : 2395

\section{Author Query Form}

\section{粤 Springer}

the language of science

\section{Please ensure you fill out your response to the queries raised below and return this form along with your corrections}

\section{Dear Author}

During the process of typesetting your article, the following queries have arisen. Please check your typeset proof carefully against the queries listed below and mark the necessary changes either directly on the proof/online grid or in the 'Author's response' area provided below

\begin{tabular}{|c|c|c|}
\hline Query & Details Required & Author's Response \\
\hline AQ1 & $\begin{array}{l}\text { Please confirm that the author names are presented accurately and in the correct sequence (given names/ } \\
\text { initials, family name). }\end{array}$ & \\
\hline AQ2 & $\begin{array}{l}\text { Journal instruction requires a city and country for affiliations. Please verify if the provided city and country } \\
\text { (Marseille Cedex 20, France; Boston, USA; Los Alamos, USA; Ames, USA) are correct and amend if } \\
\text { necessary. }\end{array}$ & \\
\hline
\end{tabular}

